\title{
CORRESPONDENCE
}

\section{End invasive chimp research now}

We disagree with your framing of chimpanzee research around past 'handsome' benefits to humankind (Nature 474, 252; 2011). These do not justify invasive experimentation in the future. The current pace of advancements in biomedical research technology means that the time has come to end invasive research on chimpanzees.

Biomedical research is replete with examples in which reliance on relatively crude, timeconsuming and expensive animal models has given way to quicker and more precise non-animal methods. For example, drug maker Eli Lilly struggled to find enough rabbits to test insulin for potency and safety when it was first purified; those tests soon gave way to mouse studies and then physicochemical methods.

Such reliance on animals was not always scientifically necessary. Take the Sabin live polio vaccine: tests in chimpanzees were simply part of a need to reassure nervous regulators that it was safe. The crucial development was cultivation of the virus in human cells - a discovery that received a Nobel prize.

The past decade has seen dozens of reports of non-animal techniques that explore the biology and pathology of hepatitis $\mathrm{C}$ virus (HCV), including a new in vitro technology that allows replication of the virus from infected patients (M. Buck PLoS ONE 3, e2660; 2008). GlaxoSmithKline runs an HCV programme that does not use chimpanzees (see go.nature.com/ eyp3wk).

Some argue that chimpanzees are still needed for testing monoclonal antibody therapeutics, but this does not stand up to scrutiny. Of the 35 monoclonal antibody therapeutics approved so far by the US Food and Drug
Administration, only three involved chimpanzee testing, and two of those were withdrawn because of side effects or lack of effectiveness (R. H. Bettauer ALTEX 28, 103-116; 2011). Andrew Rowan, Kathleen Conlee, Raija Bettauer The Humane Society of the United States, Washington DC, USA. arowan@humanesociety.org

\section{Indian vaccine study clarified}

As director of the human papillomavirus (HPV) vaccines project at the global health non-profit organization PATH, I wish to clarify some important points relating to your News story on the inquiry committee's investigation of the HPV vaccine study following the deaths of participants (Nature 474, 427-428; 2011). There were seven deaths (among nearly 24,000 girls), not four, and the inquiry committee found that none of the deaths was related to the vaccine (five definitively, two considered unlikely).

Contrary to your headline indicating that the ethics of the study have been criticized, the inquiry committee's report concludes: "There has been no major violation of any ethical norm in the conduct of the study."

PATH believes that the HPV vaccine study under review was not a 'clinical' trial because no clinical outcomes were measured. The product had already undergone clinical trials in India and elsewhere, and had been licensed and made available in the private sector throughout the country. Even so, safeguards such as ethical review and informed consent were built into the study.

You quote Jacob Puliyel's opinion that not enough is known about the burden of HPVrelated cervical cancer in India. However, the World Health
Organization estimates that India shoulders more than one-quarter of the global burden of cervicalcancer mortality (about 73,000 of 275,000 deaths per year). The HPV types countered by the vaccines in question account for the majority of these cases. It was in part owing to the high prevalence of cervical cancer in the country that PATH included India among its four study sites (similar studies were conducted in Peru, Uganda and Vietnam).

Prevention methods such as $H P V$ vaccination and screening alternatives (by visual inspection or HPV DNA testing) could substantially reduce the mortality in middle- and lowincome countries, which suffer about $88 \%$ of the burden of cervical cancer, to the low levels now common elsewhere.

To increase cost-effectiveness, we need evidence of the best way to roll out these interventions. Studies such as those completed in India (see www.rho.org) will enable the acquisition of such data.

Vivien Davis Tsu PATH, Seattle, Washington, USA.vtsu@path.org

\section{Café science for kids}

A science café, Zabuki, that we launched for children in the Dutch town of Deventer in 2008 is hugely successful - attracting around 70 schoolchildren every month (www.zabuki.nl). We also organize an annual two-day science festival with the local teacher-training schools, to which some 800 children came last year. We urge other towns to launch similar initiatives to encourage more kids to engage with science and technology.

Like science cafés for adults (Nature 399, 120; 1999), Zabuki is run by volunteers - usually parents. Trainee primary-school teachers also help regularly as part of their assignments. The children (aged 7-12) suggest themes that are developed in smaller workshops with the help of a local expert. Local companies volunteer materials and expertise.

The cafés offer children a hands-on scientific challenge in a stimulating, non-school context, where they can explore themes voluntarily that they might not otherwise investigate or discuss. Topics have included robotics, architecture and life in a ditch.

Children pay $€ 4$ (about US\$6) towards expenses and refreshments; the remainder of the $€ 700$ cost per café is sponsored by the region. Volunteers spend 2-8 hours a month organizing the cafe. Anne M. Dijkstra University of Twente, Enschede, the Netherlands.

a.m.dijkstra@utwente.nl Henk Van Voorthuizen Abilene. $n l$, Deventer, the Netherlands. Mark Van Zijtveld Deventer, the Netherlands.

\section{Rise in scientists returning to China}

Jun Li blames China's rigid citizenship regulations for hindering the return of Chinese scientists from abroad (Nature $474,285 ; 2011)$. This is an oversimplification.

Chinese scientists and engineers are much in demand abroad. But because of China's economic development and the downturn in the West, the number of returnees has risen sharply (see go.nature.com/ dfljeo). Taiwan also had a surge of trained scientists returning home during its economic boom in the late 1980s and 1990s.

Given China's buoyant economy, relaxation of China's citizenship regulations is unlikely to happen soon. Xiaoming Li Tennessee State University, Nashville, Tennessee, USA.xli1@tnstate.edu 